\title{
The Impact of Proactive Personality and Cognitive Flexibility on Situational Judgment among Student Pilots in China
}

\author{
Ming Ji ${ }^{*}$ \\ School of Psychology, Shaanxi Normal University, Xi'an, \\ Shaanxi 710062, China \\ Shaanxi Key Laboratory of Behavior and Cognitive \\ Neuroscience, \\ Xi'an, Shaanxi 710062, China \\ * Corresponding author: Ming Ji; E-mail: \\ jiming@snnu.edu.cn
}

Dan Liu

School of Psychology, Shaanxi Normal University, Xi'an, Shaanxi 710062, China

Shaanxi Key Laboratory of Behavior and Cognitive

Neuroscience,

Xi'an, Shaanxi 710062, China

\author{
Fang Jin \\ School of Psychology, Shaanxi Normal University, Xi'an, \\ Shaanxi 710062, China \\ Shaanxi Key Laboratory of Behavior and Cognitive \\ Neuroscience, \\ Xi'an, Shaanxi 710062, China
}

\section{Can Yang}

School of Psychology, Shaanxi Normal University, Xi'an, Shaanxi 710062, China

Shaanxi Key Laboratory of Behavior and Cognitive Neuroscience,

Xi'an, Shaanxi 710062, China

\section{XingXing Chen}

School of Psychology, Shaanxi Normal University, Xi'an, Shaanxi 710062, China

Shaanxi Key Laboratory of Behavior and Cognitive Neuroscience, Xi'an, Shaanxi 710062, China

\begin{abstract}
The present study was to investigate the effect of proactive personality (PAP) and cognitive flexibility (CF) on the student pilots' situational judgment. This study was based on a sample of 222 student pilots from Civil Aviation Flight University of China. The results showed that proactive personality directly affected student pilots' situational judgment. Cognitive flexibility had the moderating effect on the relationship between PAP and situational judgment. Implications of the study as well as future research directions on the study of student pilot's situational judgment are discussed.
\end{abstract}

Keywords: Proactive Personality; Cognitive Flexibility; Situational Judgment

\section{Introduction}

The majority of accidents and incidents in aviation can be attributed partially to poor decision making and judgement strategies (O’Hare, 1990). Diehl (1991) estimated that situational judgement and decision errors contributed to $56 \%$ of accidents in airlines and $53 \%$ of accidents in military aviation. As "the mental process that we use in making decisions" (Jensen, 1995), situational judgement affected significantly the pilots safety operation behavior. The effectiveness of situational judgment was mainly depended on the related factors with respect to stable trait and cognitive ability. From the pers-pective of the theoretical framework, situational judgment could be affected by personality characteristics of pilots. Personal attributes and cognitive variables are key predictors of pilot's judgment.

However, the role of personality characteristics often has been ignored when such training are carried out. In fact, personality trait is a critical variable to explain individual differences in aviation accident involvement and risk-taking behavior. Several studies have supported this hypothesis, which the self-concept control, conscientiousness, and locus of control has an inseparable nexus to the pilot's judgment (Hunter and Stewart, 2009). In addition, the indirect effect of these personality factors might be underestimated with regard to accident involvement. In particular, the role of personality in the relationship between social cognition variables and situational judgement has rarely been studied.

As implied by the previous presentation, the present study attempts to integrate both social cognition and personality approaches and provides a better understanding of the mechanisms underlying pilots' situational judgement.

\subsection{Proactive personality}

Proactive personality (PAP) is clearly defined as a stable tendency to effect environmental change (Batement and Crant, 1993). Compared with the passive one, people with 
PAP engages in alter the undesirable environment, seize opportunities and take the initiative action to achieve their goal (Crant, 2000). Among other things, PAP is also deem as a positive trait for other variables in organizational psychology, such as performance, work perception, workrelated learning (Bakker et al, 2012). Seibert et al. (1999) argued that proactive individual who are good at exerting control their work situation and understand the contingencies environment. PAP was deemed as positive trait for task-related activity. Base on the available literatures, we hypothesized that: H1: PAP will predict situational judgment.

\subsection{Cognitive flexibility}

Previous approaches to understand the nature of decision-making have also focus on the pilot's strategies. Pilot must continually adjust their cognitive and coping strategies responding on environmental demands. Although flexibility of cognitive control has become a concern, the relationship is still vague among personality, pilot's judgment and flexibility.

To achieve high safety and performance levels in complexity and uncertainty flight environment, pi-lots need to analyze the potential risk and make a judgment actively. Effective judgments not only depend on timeliness and perspetiveness, but adaptation also is a key factors. Fornette et al. (2012) showed that the pilot's cognitive adaptation are essential on situational judgment and performance through constantly adjust their cognitive strategies according to environment demands. They suggested that cognitive control processes facilitates adaptation when the dynamically, complex, or both of a given situation preclude an automatic response. Moreover, Orasanu and Martin (1998) analyzed the errors in aviation decision making and found that lack of flexibility is a vital factor. Chan (2006) also found the negative effect of PAP when one blindly takes the initiative and not effective in responding to situational demands. Specifically, proactive behaviors may be maladaptive if they can't adjust the strategy in uncertain situation. CF is a crucial ability to overcome the preferred coping strategy in changeable environment (e.g., flight environment). Given the lack of empirical studies in this domain, we can offer an exploratory hypothesis: $H 2$ : $C F$ moderates the relationship between situational judgment and PAP.

\section{Method}

\subsection{Participants}

222 male student pilots participated in this research. The student pilots ages ranged from 19 to 29 years $(M=22.38$, $\mathrm{SD}=2.56$ ) and flight time ranged from 196 to $468 \mathrm{~h}$ $(\mathrm{M}=140.02, \mathrm{SD}=114.31)$.

\subsection{Measures}

\subsubsection{Proactive personality Scale (PPS)}

We used Bateman and Crant's (1993) 10-item scale to measure PAP. Crobach's alpha of .86 in the present study. Participants indicated their agreement on a 7-point scale, ranging from 1 (strongly disagree) to 7 (strongly agree).

2.2.2. Cognitive flexibility scale

The cognitive flexibility scale is a revision of original scale (Martin and Rubin, 1995; Qi et al., 2013), which has 13 items $(\alpha=0.84)$. Participants responded on a 6-point agreement scale, ranging from 1 (strongly disagree) to 6(strongly agree).

2.2.3. Situational judgment test

Situational judgment was measured using a situational judgment test developed by Hunter (2003). There are 10 items $(\alpha=0.82)$ consists of descriptions of aviation scenarios in which decision is required of the pilot. Four plausible alternatives to each scenario and participant need to choose the best alternatives to the scenario. The participant's decision is scored (right or wrong) by reference to a key recommended by subject matter experts (SMEs).

\subsection{Data analyses}

The indictor of internal consistencies for each measure was evaluated by Cronbach's alpha coefficient. The moderating effects of cognitive flexibility on the relationship between proactive personality and situational judgment of the student pilots were estimated by using hierarchical regression analysis by SPSS 18.0.

\section{Results}

\subsection{Descriptive statistics}

The numbers of items, mean scores, standard deviations, and internal consistencies for all measures are listed in Table 1 . The reliability coefficients were acceptable in that they achieved the suggested minimum value.

Table 1 Number of items, mean scores and Cronbach's alpha for all measures.

\begin{tabular}{|c|c|c|c|c|}
\hline Measures & $N$ & $M$ & $S D$ & $\alpha$ \\
\hline $\begin{array}{l}\text { Proactive } \\
\text { Personality }\end{array}$ & 10 & $4.76^{a}$ & 1.01 & 0.86 \\
\hline $\begin{array}{l}\text { Cognitive } \\
\text { flexibility }\end{array}$ & 13 & $4.7^{\mathrm{b}}$ & 0.82 & 0.84 \\
\hline $\begin{array}{l}\text { Situational } \\
\text { judgment }\end{array}$ & 10 & $0.43^{d}$ & 0.22 & 0.82 \\
\hline
\end{tabular}

${ }^{\mathrm{a}}$ Range $1-7 ;{ }^{\mathrm{b}}$ Range $1-6 ;{ }^{\mathrm{c}}$ Range $1-10 ;{ }^{\mathrm{d}}$ Range0-1.

Bivariate correlations among the study variables are listed in Table 2. PAP was significantly correlated with situational judgment of the student pilots $(r=0.361, p<0.01)$. $\mathrm{CF}$ was significantly correlated with situational judgment of the student pilots $(r=0.344, p<0.01)$. In addition, PAP was significantly correlated with the student pilots' $\mathrm{CF}$ $(r=0.412, p<0.01)$. Consequently, the student pilots tend to 
make effective decision if they can use the flexible strategy in uncertain environment.

Table 2 inter correlations among the research variables

\begin{tabular}{|c|c|c|c|c|c|}
\hline Variables & 1 & 2 & 3 & 4 & 5 \\
\hline Age & - & & & & \\
\hline Flight time & $.763^{* *}$ & - & & & \\
\hline $\begin{array}{c}\text { Proactive } \\
\text { Personality }\end{array}$ & $.181^{* *}$ & $.200^{* *}$ & - & & \\
\hline $\begin{array}{l}\text { Cognitive } \\
\text { flexibility }\end{array}$ & .045 & .014 & $.412^{* *}$ & $.181^{* *}$ & - \\
\hline $\begin{array}{c}\text { Situational } \\
\text { judgment }\end{array}$ & $.168^{*}$ & .108 & $.361^{* *}$ & $.344^{* *}$ & $.397^{* *}$ \\
\hline
\end{tabular}

Note: $\mathrm{N}=\overline{222 \text {. Bold figures on the diagonal are alpha reliabilities }}$ of scales. $* p<.05$, ** $p<.01$.

\subsection{Moderating effect}

In this study, the moderating effect of $\mathrm{CF}$ on the relationship between situational judgment and PAP was tested by regression analysis. Results for the moderated linear hierarchical regressions are presented in Table 3. After controlling for the variables of age and flight times, PAP and CF significantly increased the overall explanation rate to safety operation behavior in the regression equation. PAP was a significant predictor $(\beta=.19, \mathrm{p}<0.001)$ on the situational judgment, while $\mathrm{CF}$ also has significantly positive effect $(\beta=.23, p<0.001)$. The interaction term of PAP and CF was significantly negative predictor $(\beta=.14$, $\mathrm{p}<0.05)$. As a consequence, $\mathrm{CF}$ moderates the relationship between situational judgment and PAP.

Table 3 Results of Regressions about the Relationships among PP, $\mathrm{CF}$, and $\mathrm{SJ}$

\begin{tabular}{|c|c|c|c|c|c|}
\hline \multirow{2}{*}{ Variables } & Mode 1 & \multicolumn{2}{|c|}{ Model 2} & \multicolumn{2}{|c|}{ Model 3} \\
\hline & $t$ & $\beta$ & $t$ & $\beta$ & $t$ \\
\hline Step 1 & & & & & \\
\hline Age & .191 .8 & .14 & 1.54 & .14 & 1.56 \\
\hline $\begin{array}{l}\text { Flight } \\
\text { time }\end{array}$ & $-.03-.32$ & -.04 & -.40 & -.04 & -.41 \\
\hline Step 2 & & & & & \\
\hline$P P$ & & .19 & $2.69^{* * *}$ & .18 & $2.60^{* *}$ \\
\hline$C F$ & & .23 & $3.31^{* *}$ & .24 & $3.4^{* * *}$ \\
\hline$P P \times C F$ & & & & -.14 & $-2.27^{*}$ \\
\hline$F$ & 3.02 & $9.46^{*}$ & & $8_{* *}^{8.75}$ & \\
\hline$R^{2}$ & .03 & .15 & & .17 & \\
\hline Adjust $R^{2}$ & .02 & .13 & & .15 & \\
\hline
\end{tabular}

To further understand the $\mathrm{CF}$ as a moderator variable on the results, scores of PAP and CF were divided into two groups to examine its effect, high group and low group. The interaction of PAP and $\mathrm{CF}$ are shown in Fig. 1. Flight cadet's situational judgment improves as CF increased both in low and high group of PAP. More specially, when the PAP scores were high, the flight cadets with high level of
$\mathrm{CF}$ exhibited the more effective situational judgment than those with low level of CF. What is more, Highly proactive individuals who are not effective in judging situation if they have low level of CF. These results show that PAP predicted the situational judgment positively when $\mathrm{CF}$ was high but negatively when $\mathrm{CF}$ was low. Consequently, the relationship between PAP and situational judgment was moderated by $\mathrm{CF}$.

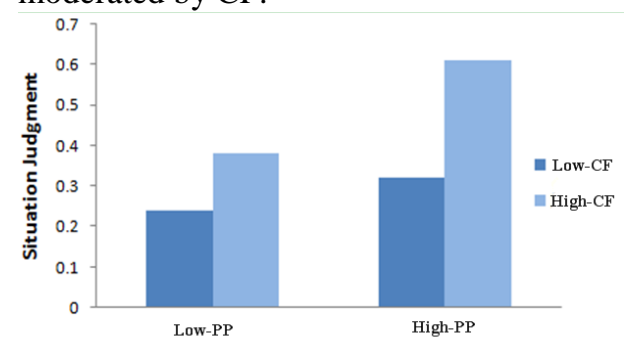

Fig. 1. The interaction effect of PAP and CF to situational judgment.

\section{CONCLUSIONS}

The results of this study indicate that PAP has direct effects on situational judgment. Proactive personality has superiority on situational judgment. Consequently, the result also shows proactive personality could be acted as an available of pilot's situational judgment in the future. The result provides us a reliable way to enhance the effectiveness of pilot's situational judgment is to select a candidate at the higher of proactive personality.

Furthermore, our results indicate that CF significantly moderated the relationship between PAP and situational judgment. Specifically, a low level of CF reduced the positive effects of PAP on situational judgment. It implies that not all proactive behavior leads to positive outcomes. Only adjust coping strategies constantly can pilots effectively make decision in complex and uncertain environment. A possible explanation is that high proactive individuals who are lack the flexibility on cognitive control often hardly overcome this tendency of unconsciously selecting the preferred strategy, especially in stress. On the other hand, CF shares several aspects with cognitive control, which necessary to intervene on un-consciously selecting and automatic processes, to solve abstract or novel problems, and anticipate the future (Evans, 2008). Therefore, the level of $\mathrm{CF}$ is crucial factor to decide whether the positive effect can give full play. The PAP $\times$ $\mathrm{CF}$ interaction has practical implications (e.g., personnel selection and training). The moderating effect implies that it may not be prudent to select flight cadets only base on the type of their personality, such as PAP. The other individual-difference variables (i.e. cognitive ability) should be tested to avoid the negative interactive effect on task.

In conclusion, the results of the present study showed that PAP directly effects situational judgment and risk 
perception mediated the relationship between PAP and situational judgment, and CF moderates the relationship between PAP and situational judgment among flight cadets. This study demonstrates that PAP is a positive trait on flight cadet's situational judgment so that higher level of risk perception and $\mathrm{CF}$ will strengthen the positive effect.

\section{Acknowledgments}

This study was supported by the National Natural Science Foundation of China (Grant No. 71301092) and supported by the Humanities and Social Science Foundation of Ministry of Education of China (Grant No. 13YJC190009). Especially, the authors would like to thank the respondents from Civil Aviation Flight University of China who answered our questionnaire.

\section{References}

[1] A. B. Bakker, M. Tims, and D. Derks. Proactive personality and job performance: The role of job crafting and work engagement. Human Relations, 65(10), 1359-1378, 2012.

[2] T. Bateman, and J. Crant. The proactive component of organizational behavior: A measure and correlates. Journal of Organizational Behavior, 14, 103-118, 1993.

[3] D. Chan. Interactive effects of situational judgment effectiveness and proactive personality on work perceptions and work outcomes. Journal of Applied Psychology, 91(2), 475-481, 2006.

[4] J. M. Crant, and T. S. Bateman. Charismatic leadership viewed from above: The impact of proactive personality. Journal of Organizational Behavior, 21, 63-75, 2000.

[5] J. S. B. Evans. Dual-processi ng accounts of reasoning, judgment, and social cognition. Annual Review of Psychology, 59, 255-278, 2008.

[6] M. P. Fornette, M. H. Bardel, C. Lefrançois, J. Fradin, F. E. Massioui, and R. Amalberti. Cognitive-Adaptation Training for Improving Performance and Stress Management of Air Force Pilots. The International Journal of Aviation Psychology, 22(3), 203-223, 2012.

[7] D. R. Hunter. Measuring general aviation judgment using a situational judgment technique. International Journal of Aviation Psychology, 13, 373-386, 2003.

[8] D. R. Hunter, and J. E. Stewart. Locus of control, risk orientation, and decision making among U.S. army aviators (Tec. Rep. No. 1260). U.S. Army Research Institute or the Behavioral and Social Sciences (DTIC No. ADA452056), Arlington, VA, 2009.

[9] R. S. Jensen. Pilot judgment and crew resource management. Brookfield, VT: Avebury, 1995.

[10] D. O'Hare. Pilots' perception of risks and hazards in general aviation. Aviation, Space, and Environmental Medicine. 61(7), 599-603, 1990.

[11] J. Orasanu, and L. Martin. Errors in aviation decision making: A factor in accidents and incidents. In Proceedings of the Workshop on Human Error, Safety, and Systems Development, 1998.

[12] B. Qi, and B. Zhao, K. Wang, and H. H. Liu. Revision and preliminary application of cognitive flexibility scale for college students. Studies of Psychology and Behavior, 11(1), 120-123, 2013. 